\title{
NIH panel rejects Persian Gulf Syndrome
}

Washington. An advisory panel to the US National Institutes of Health (NIH) recommended after a three-day meeting last week that a health survey be carried out of the nearly 700,000 individuals who served in the Persian Gulf during the war with Iraq at the beginning of 1991 .

The panel has also recommended that extensive research be carried out into unexplained symptoms being reported by veterans of the Gulf War. But it has rejected the suggestion that the illnesses represented by these symptoms constitute a single medical syndrome, as some scientists and veterans have argued.

The symptoms reported include fatigue, skin rash, muscle and joint pain, headaches, loss of memory, shortness of breath, gastrointestinal and respiratory symptoms, and extreme sensitivity to commonly occurring chemicals. The panel was set up to examine whether the symptoms were caused by conditions in the Gulf, and to decide if they should be classified as a single Gulf War Syndrome.

Many veterans are now unable to work because of such symptoms, but do not qualify for a disability allowance because their symptoms do not fit any of the diagnostic criteria used by the Department of Veterans Affairs when determining eligibility for disability payments. Advocacy groups for veterans add that there are many men and women still serving in the armed forces who are reluctant to report their symptoms for fear of being labelled as malingerers.

Last week's meeting at the NIH was prompted by a combination of the veterans'

\section{Boyer makes gift of \$24 million to UCSF}

San Francisco. Herbert Boyer, emeritus professor of biochemistry at University of California-San Francisco and co-founder of Genentech Inc., one of the most successful US biotechnology companies, has donated $\$ 24$ million to the school, the university announced last week.

The gift consists of Boyer's portion of the patent rights to the process of splicing genes, estimated to be worth about \$24 million over the patent's 17 years of life up to 1997. Boyer and Stanley Cohen of Stanford University are both credited with the discovery and both universities have shared patent rights with the inventors. It is one of UCSF's most lucrative patents.

The university said it would use the gift to the department of biochemistry to support the development of advanced biomedical research. It is the largest personal donation made to any of the nine University of California campuses.

S. L. anger and pressure from Congress. At one point Major General Ronald Blanck, commander of the Walter Reed Army Medical Center in Washington, called for the panel to define a Persian Gulf Syndrome. Even if that was not the best scientific opinion, he said, some definition was necessary to enable the veterans to claim disability.

After a private discussion lasting until the early hours of Friday morning, the panel concluded that there is no such thing as Persian Gulf Syndrome. But it acknowledged that people were suffering real illnesses. Herbert Schaumburg, a panel mem-

\section{IMAGE UNAVAILABLE FOR COPYRIGHT REASONS}

Did safety precautions cause later illness?

ber who is chairman of the Department of Neurology at the Albert Einstein College of Medicine in New York, said: "I came here with a mind-set that these people were malingering, but I am now convinced that there is real pain and suffering."

Many veterans, who travelled to the NIH campus at their own expense, used the meeting to attack the US government, creating an emotionally-charged atmosphere very different from the usual academic mood of an $\mathrm{NIH}$ consensus meeting. By the third day, veterans advocates admitted that the NIH panel was behaving with integrity, and aimed their anger at the Departments of Defense (DoD) and Veterans Affairs.

Some panel members appeared to feel the same frustration with the DoD as did the veterans. When asked if they were satisfied with the DoD's response to the veterans and to their work, most panel members looked uncomfortable, even though remaining silent.

But John Spengler, of the Harvard School of Public Health, complained that, even though it was nearly three years since the end of hostilities, basic information was still not available. "Even when troops were exposed for a long time, we were unable to find any records of exposure."

The Department of Veterans Affairs has information on the health of only about 20,000 of the 700,000 American men and women who served in the Gulf. Furthermore, there is no detailed knowledge about which of the many noxious substances in the Gulf each person was exposed to. It was the lack of such knowledge that led the panel to make its recommendations for extensive research and a health survey.

A further complication is that the actual exposure often differs from the official history. One example concerns pyridostigmine bromide (PB), a drug administered to reduce the effects of nerve gas, which was given to nearly 400,000 troops.

The troops were supposed to take the drug for 72 hours at a time, interrupted by 24 hours, during periods of heightened alert for attack by chemical weapons. In fact, says Irving Cohen, a physician with the Veterans Administration Medical Center in Topeka,

Kansas, some units took the drug "every day they were in the Gulf'.

PB has unpleasant side effects because it works in the same way as a nerve gas. Both PB and nerve gas bind to and inactivate an enzyme (acetyl cholinesterase) that breaks down acetyl choline - the compound which stimulates nerve action. Nerve gas binds irreversibly, and the resulting lack of enzyme to break down acetyl choline leads to a massive overstimulation of muscle. The body is unable to synthesize new enzyme in time to prevent death.

PB was given to the troops because it binds reversibly to acetyl cholinesterase. It works on the principle that if it is bound to between 20 and 40 per cent of acetyl cholinesterase, the binding can be reversed after a nerve gas attack, freeing up enzymes to break down enough acetyl choline to reduce muscle spasms.

The DoD defends its distribution of $\mathrm{PB}$ on the basis that much higher doses of $\mathrm{PB}$ have been administered for years to people suffering from myasthenia gravis, with few side-effects. For this reason, the panel accepted that PB was unlikely to be the main cause of some of the symptoms now being experienced. But they did not rule out $\mathrm{PB}$ completely, as little is known of how stress affects the body's response to low doses.

Although the NIH panel did not agree on the cause of the range of illnesses being observed, it did conclude that post-traumatic stress syndrome, as well as a new form of the parasitic disease leishmaniasis, could each be attributed to service in the Gulf. So far 31 cases of leishmaniasis have been confirmed among Gulf veterans, but the panel believes there may be more subclinical cases, and a ban therefore remains in force against Gulf War veterans donating blood.

The panel did not rule out any of the suggested reasons for the symptoms being observed, including reports from troops that they were exposed to chemical and biological warfare. Eula Bingham of the University of Cincinnati College of Medicine, said there was no reason to disbelieve a Czech government report that troops had been exposed to chemical weapons. Helen Gavaghan 